\title{
Análise comparativa de quatro kits de FAN HEp-2 para a detecção de autoanticorpos séricos
}

\section{Comparative analysis of four ANA HEp-2 kits for the detection of serum autoantibodies}

Rômulo Carvalho Vaz de Mello;; Dilermando Fazito de Rezende²; Bárbara Ribeiro Coutinho; Clarissa de Souza Medeiros4; Enoque Ananias Alves Filho ${ }^{5}$; Giovanni César Leite ${ }^{6}$; João Paulo Ferreira de Carvalho ${ }^{7}$; Suzane Pretti Figueiredo Neves ${ }^{8}$

\section{unitermos}

Autoanticorpos

Anticorpos antinúcleo

FAN HEp-2

Doenças autoimunes

\section{resumo}

Introdução: $\mathrm{O}$ objetivo deste estudo foi avaliar a concordância entre os kits de fator antinúcleo (FAN) HEp-2 em relação aos padrões de fluorescência observados. Objetivou-se, ainda, avaliar o desempenho dos kits em relação à intensidade de fluorescência apresentada pelo uso dos conjugados fluorescentes, o número de mitoses por campo presentes no poço de reação e a titulação necessária para se obter o limiar de reatividade mínima (1+) dos soros controle reagentes presentes nos kits. Materiais e métodos: Setenta e quatro amostras com resultados conhecidos foram testadas em quatro kits comerciais para a pesquisa de FAN HEp-2. O processamento estatístico foi feito pelo programa STATA ${ }^{\circledR} 9.2$ e a concordância entre os resultados foi aferida pelo teste Kappa. Resultados: $\mathrm{O}$ índice de concordância entre os kits, obtido pelo teste Kappa, foi superior a 0,94 . Houve grande variabilidade quanto ao número de mitoses por campo presentes por poço de reação e quanto à intensidade de fluorescência dos conjugados, além de ter havido significativa diferença em dois kits em relação à diluição necessária para obtenção do limiar de reatividade mínima (1+). Conclusão: A taxa de concordância geral obtida pelo teste Kappa foi elevada, atingindo índice superior a 0,94. As maiores diferenças foram devido à presença de amostras com padrão variando entre nuclear pontilhado fino (PF), nuclear pontilhado fino denso (PFD) e nuclear homogêneo (HOMO). É necessária maior padronização dos kits quanto ao soro controle para a obtenção do limiar de reatividade mínima e em relação à intensidade de fluorescência dos conjugados.

\section{abstract}

Introduction: The objective of this study was to assess the concordance among antinuclear antibody (ANA) HEp-2 kits as to the observed fluorescent patterns. The objective was also to evaluate their performance concerning the following items: fluorescence intensity due to the use of fluorescent conjugates, the number of mitosis per field on the reaction wells, and the required dilution to obtain minimum reactivity (1+) of the reagent control-serum present in the kits. Material and methods: Seventy-four samples previously known results were tested using four commercial kits ANA HEp-2 kits. The statistical evaluation was carried out with STATA ${ }^{\circledast} 9.2$ software and the concordance among the results was assessed with Kappa test. Results: The concordance coefficient among the kits obtained with Kappa test was higher than 0.94. There was a great variability as to the number of mitosis per field on the reaction wells and the intensity of fluorescence conjugates. Concerning the required dilution to obtain a minimum reactivity (1+), there was a significant difference in two kits. Conclusion: The general concordance level obtained with Kappa test was higher than 0.94. The greatest differences were observed in samples with nuclear fine speckled (FS), nuclear dense fine speckled (DFS) and nuclear homogeneous (HOMO) patterns. As far as serum for minimum reactivity level and intensity of fluorescent conjugates are concerned, a better standardization is yet to be pursued. key words

Autoantibodies

Antinuclear antibodies

ANA HEP-2

Autoimmune diseases

1. Mestre em Patologia Geral pela Universidade Federal de Minas Cerais (UFMG); patologista clínico; professor da Faculdade de Medicina de Barbacena-Fundação José Bonifácio Lafayette de Andrada (FAME-FUNJOB).

2. Epidemiologista; professor de Metodologia Científica da FAME-FUNJOB

3. Graduanda da FAME-FUNJOB.

4. Graduanda da FAME-FUNJOB.

5. Graduando da FAME-FUNJOB.

6. Graduando da FAME-FUNJOB.

7. Graduando da FAME-FUNJOB.

8. Patologista clínica; doutora em Ciências pela Fundação Oswaldo Cruz (FIOCRUZ); professora adjunta do Departamento de Propedêutica da Faculdade de Medicina da Universidade Federal de Minas Cerais (UFMG). 


\section{Introdução}

Durante muito tempo, o diagnóstico das enfermidades era realizado com base na anamnese e no exame físico do paciente, fundamentados basicamente na arte da observação. Com o avanço da tecnologia, a medicina ganhou o amparo de propedêuticas laboratoriais e de imagem, que, consequentemente, permitiram a confirmação de diagnósticos menos prováveis ${ }^{(5)}$. No início da década de 1940, Hargraves notou no soro de pacientes portadores de lúpus eritematoso sistêmico (LES) a presença de material amorfo fagocitado dentro do citoplasma de neutrófilos. Descobriu-se posteriormente que esse material era constituído de proteínas do núcleo celular ligadas a anticorpos da imunoglobulina da classe $\mathrm{G}(\lg \mathrm{G})$. O teste desenvolvido a partir dessa descoberta recebeu o nome de pesquisa de célula $L E$, exame altamente específico para o diagnóstico dessa enfermidade, que, todavia, apresentava baixíssima sensibilidade, além de ser de difícil padronização e possuir baixa reprodutibilidade ${ }^{(9)}$.

Alguns anos depois, foi desenvolvido o teste de imunofluorescência indireta (IFI), utilizando inprints ou cortes histológicos de fígado de roedores como substrato, em que se buscava revelar, por meio da imunofluorescência indireta, a ligação de autoanticorpos a proteínas do núcleo das células; esse exame passou a ser conhecido como fator antinúcleo (FAN). A utilização desse teste permitiu a detecção de maior número de autoanticorpos, direcionados a diferentes proteínas do núcleo celular, resultando em positividade para o teste em várias doenças autoimunes, como Síndrome de Sjögren, esclerose sistêmica progressiva, polimiosite e outras, levando a um aumento da sensibilidade e queda na especificidade do teste. A visualização ao microscópio permitia a determinação do padrão observado pela fluorescência, que podia variar de acordo com o tipo de anticorpo presente no soro do paciente, servindo como parâmetro complementar na interpretação do teste, pois anticorpos diferentes apresentavam especificidades diferentes, associando-se mais comumente a determinadas situações clínicas. A especificidade do anticorpo podia então ser confirmada por testes específicos, como a imunodifusão radial dupla e a hemaglutinação indireta ${ }^{(1)}$.

No início dos anos 1990, foi desenvolvida uma nova metodologia para a realização do teste de FAN por intermédio da substituição das células de fígado de roedores por células da linhagem HEp-2, provenientes de carcinoma de laringe humana. A utilização desse substrato promoveu uma verdadeira revolução no teste do FAN. Por se tratar de uma célula humana e derivada de linhagem tumoral, a oferta de antígenos aumentou de forma significativa. As células também eram maiores, apresentando núcleo volumoso, 0 que facilitava a observação pela microscopia. Além disso, notou-se a presença de muitas células em diferentes estágios da mitose, o que possibilitou a exposição de antígenos relacionados com a divisão celular. A utilização das células HEp-2 levou, então, à descoberta de novos padrões de fluorescência nuclear relacionados com diferentes autoanticorpos, além de padrões citoplasmáticos, e associados à divisão celular ${ }^{(13)}$. A sensibilidade do teste aumentou de forma significativa, novamente com perda da especificidade. Observou-se, ainda, que indivíduos saudáveis e portadores de outras doenças não autoimunes poderiam apresentar reatividade para o teste. Novos testes específicos foram desenvolvidos para a detecção de anticorpos relacionados com determinados padrões de fluorescência. O teste do FAN passou a ser denominado FAN HEp-2 e, progressivamente, a ser utilizado como teste para rastreamento de doenças autoimunes. No entanto, a utilização indiscriminada do teste em populações com baixa prevalência de doenças autoimunes levou a um aumento expressivo nos resultados falso-positivos $(5,7,11,12,14,15,17,18)$.

Com o objetivo de estabelecer parâmetros para a realização do teste, padronizar a liberação dos laudos e, por conseguinte, orientar a interpretação dos resultados do teste do FAN HEp-2, foi elaborado em nosso país o Consenso Brasileiro de FAN HEp-2, que se encontra em sua terceira edição( ${ }^{(2,3,8)}$.

Entretanto, algumas questões associadas ao desempenho analítico do teste do FAN HEp-2 ainda não estão bem determinadas pela literatura. Existem várias marcas de kits comerciais destinados à realização do teste, porém não se sabe se há padronização dos materiais utilizados para a realização do exame por diferentes fabricantes, incluindo o substrato de células HEp-2, o conjugado fluorescente, e os soros controle, o que pode afetar, de maneira importante, a reprodutibilidade dos resultados obtidos por diferentes kits.

Os objetivos deste estudo foram avaliar a concordância entre quatro kits comerciais de FAN HEp-2 em relação aos padrões de fluorescência, o número de mitoses por poço de reação de cada kit e a intensidade de fluorescência de cada um dos quatro conjugados dos respectivos kits, além de verificar a diluição necessária para alcançar o limiar de reatividade mínima (1+) do soro controle positivo fornecido pelo fabricante de cada um dos kits. 


\section{Materiais e métodos}

Foram utilizadas 74 amostras de soro humano previamente testadas para pesquisa de autoanticorpos pelo método do FAN HEp-2 por IFI, gentilmente cedidas por dois grandes serviços de Medicina Laboratorial, consistindo em 10 padrões de FAN HEp-2 mais frequentemente encontrados nas amostras testadas nessas instituições. Os ensaios foram realizados no Departamento de Propedêutica Complementar da Faculdade de Medicina da Universidade Federal de Minas Gerais (UFMG).

Utilizaram-se quatro kits comerciais para a pesquisa de FAN HEp-2 por IFI de fabricantes diferentes. O kit Imuno-CON ANA HEp-2 do fabricante Wama ${ }^{\circledast}$ (Ref.: 12100-I-100) foi denominado Kit 1; o kit IFA ANA HEp-2 lgG Viroimmun ${ }^{\circledast}$ (Ref.: IF 109), Kit 2; o kit ANA/HEp-2 lgG (Anticorpos Antinucleares IgC) - Hemagen ${ }^{\circledast}$ (Ref.: 902345), Kit 3; e o kit NOVA LiteT HEp-2 ANA Kit Inova ${ }^{\circledR}$ (Ref.: 708100), Kit 4.

Os soros não reagente e reagente no limiar de reatividade mínima (1+) utilizados na análise foram obtidos no Serviço de Medicina Laboratorial, Setor de Soro-Imunologia, do Hospital das Clínicas da UFMG, consistindo de soros validados para uso na rotina do setor, sendo considerados os controles de referência para a realização da pesquisa ${ }^{(1)}$. Chamaremos esses soros de soros controle caseiros. Os controles comerciais dos kits e demais reagentes foram preparados conforme a instrução dos fabricantes.

A leitura das lâminas foi realizada em microscópio de epifluorescência da marca Olimpus, com lâmpada de vapor de mercúrio de 100 watts de potência, por dois observadores experientes, em aumento de 400 vezes.

A classificação das amostras em reagentes ou não reagentes foi feita por meio da comparação entre a intensidade de fluorescência observada para a amostra e a intensidade da fluorescência observada para o soro controle caseiro usado no limiar de reatividade mínima (1+). A classificação e a descrição dos padrões de fluorescência observados foi feita seguindo as determinações do III Consenso Brasileiro de FAN HEp-2.

Todos os controles e amostras foram testados nos quatro kits selecionados para a pesquisa. A comparação entre os padrões de fluorescência foi feita por análise visual em microscopia de fluorescência, na diluição inicial de 1:80. Após as leituras, foi feito o cruzamento entre os resultados obtidos pelos observadores e feita a reavaliação no caso de discordâncias.

Para a avaliação da diluição necessária para o estabelecimento do limiar de reatividade mínimo proposto pelos fabricantes para os soros controle reagentes dos kits, foi realizada a diluição dos mesmos com tampão PBS, partindo-se inicialmente de uma diluição de 1:40 até atingir uma diluição acima da recomendada pelo fabricante. A observação da fluorescência foi feita comparando-se com o soro controle caseiro, diluído até o limiar de reatividade mínima. A análise foi feita utilizando-se o mesmo substrato e o mesmo conjugado para todos os soros controle.

Para a avaliação do número de mitoses por campo, foi selecionada uma amostra reagente com padrão misto do tipo nuclear pontilhado fino com fluorescência do aparelho mitótico (NUMA), em virtude da facilidade de observação da placa metafásica nesse padrão. A amostra foi testada em cinco pocinhos de diferentes lâminas de cada um dos kits e foi feita a contagem do número de células e de células em mitose por campo.

Para a comparação entre a intensidade da fluorescência dos conjugados dos quatro kits, foi realizada a avaliação visual do soro controle caseiro reagente no limiar de reatividade mínima, testado na mesma lâmina com cada um dos quatro conjugados. A fluorescência foi classificada em cruzes, sendo que + : intensidade de fluorescência adequada para o sistema óptico utilizado; ++, +++ ou ++++: intensidade de fluorescência superior à adequada para o sistema óptico utilizado; e \pm : intensidade de fluorescência inferior à adequada para o sistema óptico utilizado.

A análise dos dados foi feita em microcomputador com recurso de processamento estatístico do software STATA ${ }^{\circledR}$ 9.2. Foi elaborada distribuição de frequência e foram calculados desvios-padrão, médias e percentuais indicados para cada variável. A concordância entre os resultados dos quatro kits foi aferida pelo teste Kappa para múltiplos raters ou examinadores. O nível de significância da análise foi de 5\%.

\section{Resultados}

\section{Avaliação da concordância na determinação dos padrões de FAN HEp-2 entre os quatro kits}

A distribuição da frequência dos padrões de imunofluorescência observada em cada um dos kits mostra que o padrão reagente para FAN HEp-2 mais comum foi o PFD, ao passo que o menos comum foi o padrão misto do tipo nuclear pontilhado e nucleolar pontilhado fino com placa metafásica corada ( $\mathrm{SCL}$ ). Sete dos onze padrões testados apresentaram frequência idêntica nos quatro kits: citoplasmático pontilhado polar (CPP), nuclear pontilhado 
centromérico (CEN), citoplasmático pontilhado reticulado (CPR), padrão misto do tipo NUMA, padrão misto do tipo nuclear pontilhado e SCL, nuclear pontilhado grosso (PG) e padrão nuclear pontilhado pontos isolados (NPI). Os quatro padrões que apresentaram frequências diferentes em um ou mais kits foram HOMO, PF, o nucleolar (NO) e PFD. A frequência do teste não reagente também não foi coincidente em todos os kits, uma vez que se apresentou maior no Kit 3 (28,3\%) quando em comparação com a dos demais kits (27\%) (Tabela 1).

A análise mostra que houve concordância na determinação do padrão de fluorescência, utilizando-se os quatro diferentes kits em 69 das 74 amostras (93\%). Cinco amostras discordaram quanto ao tipo de padrão fluorescente (Tabela 2).

A avaliação da taxa de concordância observada entre os quatro kits, pareados dois a dois, mostra que, entre os padrões discordantes nos quatro kits, as maiores variações foram observadas em relação aos padrões PFD e PF. Apesar disso, verifica-se que o percentual de concordância observado pode ser considerado elevado, com taxa superior a $75 \%$ em todas as comparações entre os quatro kits (Tabela 3).

A análise de concordância obtida na comparação entre os quatro kits, pareados dois a dois, para todas as combinações possíveis de visualização obtidas por kit mostrou

\section{Tabela 1 Padrões de imunofluorescência visualizados em cada um dos quatro kits, ordenados por frequência}

\begin{tabular}{|l|c|c|c|c|c|c|c|c|}
\hline Padrões & \multicolumn{3}{|c|}{ Kit 1 } & \multicolumn{3}{|c|}{ Kit 2 } & \multicolumn{3}{|c|}{ Kit 3 } & \multicolumn{3}{|c|}{ Kit 4 } \\
\hline visualizados & $n$ & $\%$ & $n$ & $\%$ & $n$ & $\%$ & $n$ & $\%$ \\
\hline NR & 20 & 27 & 20 & 27 & 21 & 28,3 & 20 & 27 \\
\hline PFD & 8 & 10,8 & 10 & 13,5 & 8 & 10,8 & 9 & 12,1 \\
\hline PF & 7 & 9,4 & 7 & 9,4 & 9 & 12,1 & 8 & 10,8 \\
\hline HOMO & 6 & 8,1 & 4 & 5,4 & 5 & 6,8 & 4 & 5,4 \\
\hline CEN & 6 & 8,1 & 6 & 8,1 & 6 & 8,1 & 6 & 8,1 \\
\hline CPR & 5 & 6,8 & 5 & 6,8 & 5 & 6,8 & 5 & 6,8 \\
\hline NO & 5 & 6,8 & 5 & 6,8 & 3 & 4 & 5 & 6,8 \\
\hline NUMA & 5 & 6,8 & 5 & 6,8 & 5 & 6,8 & 5 & 6,8 \\
\hline PG & 5 & 6,7 & 5 & 6,7 & 5 & 6,7 & 5 & 6,7 \\
\hline NPI & 4 & 5,4 & 4 & 5,4 & 4 & 5,4 & 4 & 5,4 \\
\hline CPP & 2 & 2,7 & 2 & 2,7 & 2 & 2,7 & 2 & 2,7 \\
\hline SCL & 1 & 1,3 & 1 & 1,3 & 1 & 1,3 & 1 & 1,3 \\
\hline
\end{tabular}

NR: não reagente; PFD: nuclear pontilhado fino denso; PF: nuclear pontilhado fino; HOMO: nuclear homogêneo; CEN: nuclear pontilhado centromérico; CPR: citoplasmático pontilhado reticulado; NO: nucleolar; NUMA: nuclear pontilhado fino com fluorescência do aparelho mitótico; PG: nuclear pontilhado grosso; NPI: nuclear pontilhado pontos isolados; CPP: citoplasmático pontilhado polar; SCL: nucleolar pontilhado fino com placa metafásica corada.

Amostras discordantes para a determinação do padrão de fluorescência Tabela 2 nos quatro kits de FAN HEp-2

\begin{tabular}{|c|c|c|c|c|}
\hline Amostra & Kit 1 & Kit 2 & Kit 3 & Kit 4 \\
\hline$N^{0} 7$ & HOMO & PFD & PFD & PFD \\
\hline$N^{0} 12$ & HOMO & PFD & HOMO & PFD \\
\hline$N^{0} 18$ & PFD & PFD & PF & PF \\
\hline$N^{0} 20$ & NO & NO & NR & NO \\
\hline$N^{0} 22$ & NO & NO & PF & NO \\
\hline
\end{tabular}

FAN: fator antinúcleo; HOMO: nuclear homogêneo; PFD: nuclear pontilhado fino denso; NO: nucleolar; PF: nuclear pontilhado fino; NR: não reagente. concordância em 69 (93\%) das 74 amostras pesquisadas, com índice de Kappa superior a 0,94. Os kits 2 e 4 apresentaram a maior taxa de concordância na visualização dos 14 padrões estudados, quando pareados e analisados, apresentando o maior valor de Kappa $(0,98)$ em comparação com os demais kits pareados. A comparação da concordância entre os kits 1 e 3 e entre os kits 2 e 3 foi a menor, com índice de Kappa de 0,94. Mesmo assim, um resultado bastante expressivo, que demonstra o alto grau de concordância entre os kits analisados globalmente (Tabela 4).

O cálculo de Kappa em modelo de concordância simultânea em todos os kits para os diversos padrões reagentes 
Número e percentual de amostras concordantes entre os padrões de imunofluorescência observados Tabela 3 nos quatro kits, pareados dois a dois

\begin{tabular}{|c|c|c|c|c|c|c|c|}
\hline \multirow{2}{*}{ Padrões de FAN } & \multicolumn{7}{|c|}{ Kits } \\
\hline & Concordantes & $1 \times 2$ & $1 \times 3$ & $1 \times 4$ & $2 \times 3$ & $2 \times 4$ & $3 \times 4$ \\
\hline \multirow{2}{*}{ NR } & Número (n) & 20 & 20 & 20 & 20 & 20 & 20 \\
\hline & Percentual (\%) & 100 & 95,2 & 100 & 95,2 & 100 & 100 \\
\hline \multirow{2}{*}{ PFD } & Número (n) & 8 & 7 & 7 & 8 & 9 & 8 \\
\hline & Percentual (\%) & 80,0 & 87,5 & 77,8 & 100 & 100 & 88,9 \\
\hline \multirow{2}{*}{ PF } & Número (n) & 7 & 7 & 7 & 7 & 7 & 8 \\
\hline & Percentual (\%) & 100 & 77,8 & 87,5 & 77,8 & 87,5 & 100 \\
\hline \multirow{2}{*}{ HOMO } & Número (n) & 4 & 5 & 4 & 4 & 4 & 4 \\
\hline & Percentual (\%) & 100 & 100 & 100 & 80,0 & 100 & 100 \\
\hline \multirow{2}{*}{ NO } & Número (n) & 5 & 3 & 5 & 3 & 5 & 3 \\
\hline & Percentual (\%) & 100 & 100 & 100 & 100 & 100 & 60,0 \\
\hline \multirow{2}{*}{ CEN } & Número (n) & 6 & 6 & 6 & 6 & 6 & 6 \\
\hline & Percentual (\%) & 100 & 100 & 100 & 100 & 100 & 100 \\
\hline \multirow{2}{*}{ CPR } & Número (n) & 5 & 5 & 5 & 5 & 5 & 5 \\
\hline & Percentual (\%) & 100 & 100 & 100 & 100 & 100 & 100 \\
\hline \multirow{2}{*}{ NUMA } & Número (n) & 5 & 5 & 5 & 5 & 5 & 5 \\
\hline & Percentual (\%) & 100 & 100 & 100 & 100 & 100 & 100 \\
\hline \multirow{2}{*}{$P G$} & Número (n) & 5 & 5 & 5 & 5 & 5 & 5 \\
\hline & Percentual (\%) & 100 & 100 & 100 & 100 & 100 & 100 \\
\hline \multirow{2}{*}{ NPI } & Número (n) & 4 & 4 & 4 & 4 & 4 & 4 \\
\hline & Percentual (\%) & 100 & 100 & 100 & 100 & 100 & 100 \\
\hline \multirow{2}{*}{ CPP } & Número (n) & 2 & 2 & 2 & 2 & 2 & 2 \\
\hline & Percentual (\%) & 100 & 100 & 100 & 100 & 100 & 100 \\
\hline \multirow{2}{*}{$S C L$} & Número (n) & 1 & 1 & 1 & 1 & 1 & 1 \\
\hline & Percentual (\%) & 100 & 100 & 100 & 100 & 100 & 100 \\
\hline
\end{tabular}

FAN: fator antinúcleo; NR: não reagente; PFD: nuclear pontilhado fino denso; PF: nuclear pontilhado fino; HOMO: nuclear homogêneo; NO: nucleolar; CEN: nuclear pontilhado centromérico; CPR: citoplasmático pontilhado reticulado; NUMA: nuclear pontilhado fino com fluorescência do aparelho mitótico; PG: nuclear pontilhado grosso; NPI: nuclear pontilhado pontos isolados; CPP: citoplasmático pontilhado polar; SCL: nucleolar pontilhado fino com placa metafásica corada.

\section{Análise da concordância obtida na comparação dos quatro kits, pareados dois a dois, para todas} Tabela 4 as combinações possíveis de visualizações feitas por kit

\begin{tabular}{|c|c|c|c|}
\hline Kits comparados & Concordância observada & Concordância esperada & Kappa (limites inferior e superior) \\
\hline $1 \times 2$ & 97,3 & 12,8 & $0,97(0,88-1,05)$ \\
\hline $1 \times 3$ & 94,6 & 13,2 & $0,94(0,86-1)$ \\
\hline $1 \times 4$ & 95,9 & 12,9 & $0,95(0,87-1,03)$ \\
\hline $2 \times 3$ & 94,6 & 13,3 & $0,94(0,86-1,02)$ \\
\hline $2 \times 4$ & 98,7 & 13,1 & $0,98(0,90-1,06)$ \\
\hline $3 \times 4$ & 96 & 13,3 & $0,95(0,87-1,03)$ \\
\hline
\end{tabular}


também mostrou concordância igual a 1 em sete dos 11 padrões, com concordância combinada acima de 0,94. Esses resultados mostram que os quatro kits foram capazes de reproduzir em alto grau os padrões estudados. Ainda que os padrões HOMO, PF e PFD apresentem Kappa inferior a 0,95 , pode-se observar que o menor valor de Kappa obtido pelas análises ainda é significativamente alto, situando-se sempre acima de 0,85 (Tabela 5).

\begin{tabular}{|c|c|c|c|}
\hline \multirow{2}{*}{$\begin{array}{c}\text { Iabela } 5 \text { padroes } \\
\text { Padrões visualizados }\end{array}$} & \multicolumn{3}{|c|}{$\begin{array}{l}\text { para concordância simultânea dos quatro kits na visualização de } 12 \\
\text { ação destes }\end{array}$} \\
\hline & Kappa & Z & $p$ \\
\hline NR & 0,983 & 20,71 & $<0,001$ \\
\hline PFD & 0,881 & 18,57 & $<0,001$ \\
\hline PF & 0,915 & 19,30 & $<0,001$ \\
\hline HOMO & 0,869 & 18,31 & $<0,001$ \\
\hline NO & 0,882 & 18,58 & $<0,001$ \\
\hline CEN & 1 & 21,07 & $<0,001$ \\
\hline CPR & 1 & 21,07 & $<0,001$ \\
\hline NUMA & 1 & 21,07 & $<0,001$ \\
\hline$P G$ & 1 & 21,07 & $<0,001$ \\
\hline NPI & 1 & 21,07 & $<0,001$ \\
\hline CPP & 1 & 21,07 & $<0,001$ \\
\hline SCL & 1 & 21,07 & $<0,001$ \\
\hline Combinado & 0,955 & 55,79 & $<0,001$ \\
\hline
\end{tabular}

NR: não reagente; PFD: nuclear pontilhado fino denso; PF: nuclear pontilhado fino; HOMO: nuclear homogêneo; NO: nucleolar; CEN: nuclear pontilhado centromérico; CPR: citoplasmático pontilhado reticulado; NUMA: nuclear pontilhado fino com fluorescência do aparelho mitótico; PG: nuclear pontilhado grosso; NPI: nuclear pontilhado pontos isolados; CPP: citoplasmático pontilhado polar; SCL: nucleolar pontilhado fino com placa metafásica corada.

\section{Avaliação do número médio de mitoses por campo}

A análise do número médio de mitoses por campo, com aumento de 400 vezes, mostrou que o maior número encontrado foi no Kit 1, com valor médio de 4,6 mitoses por campo, contra um valor de 1,4 mitose por campo no Kit 3, o de menor valor. A avaliação do número de mitoses presentes por célula visualizada demonstrou novamente que o Kit 1 apresentou o índice mais elevado, sendo que para cada 19 células visualizadas por campo uma correspondia a uma célula em mitose (Tabela 6).

\begin{tabular}{l|l|l|l|l|l} 
& \multicolumn{5}{c}{ Avaliação do número de mitoses por } \\
Tabela 6 & Kampo com aumento de & $\mathbf{4 0 0}$ vezes \\
\hline & Kit 1 & Kit 2 & Kit 3 & Kit 4 \\
\hline $\begin{array}{l}\text { Número de } \\
\text { mitoses }\end{array}$ & $\begin{array}{l}4,6 / \\
\text { campo }\end{array}$ & $\begin{array}{l}2,3 / \\
\text { campo }\end{array}$ & $\begin{array}{l}1,4 / \\
\text { campo }\end{array}$ & $\begin{array}{l}1,6 / \\
\text { campo }\end{array}$ \\
\hline $\begin{array}{l}\text { Relação célula/ } \\
\text { mitose }\end{array}$ & 19 & 42 & 36 & 32 \\
\hline
\end{tabular}

\section{Avaliação da intensidade de fluorescência dos conjugados}

Foi observada pequena variação na verificação da intensidade de fluorescência dos conjugados de cada um dos quatro kits usados na pesquisa, utilizando-se o soro controle caseiro reagente no limiar de reatividade mínima como parâmetro de avaliação. $\mathrm{O}$ conjugado do Kit 1 apresentou resultado satisfatório, reproduzindo adequadamente uma fluorescência de reatividade limiar (1+) na diluição recomendada, enquanto o conjugado do Kit 2 mostrou intensidade de fluorescência acima do esperado ( $>1+$ ). Os conjugados dos Kits 3 e 4 apresentaram intensidade de fluorescência mais baixa (Tabela 7).

\section{Tabela 7 mínima}

Avaliação da intensidade de fluorescência dos conjugados na visualização do soro controle reagente no limiar de reatividade

\begin{tabular}{l|c|c|c|c}
\hline & Kit 1 & Kit 2 & Kit 3 & Kit 4 \\
\hline Soro controle $1+$ & + & $>1+$ & \pm & \pm \\
\hline
\end{tabular}




\section{Verificação dos títulos dos soros controle comerciais}

A verificação da diluição necessária para fornecer o limiar de reatividade mínima dos soros controle reagentes de cada kit demonstrou concordância entre o valor da diluição proposta pelo fabricante e aquele encontrado neste estudo somente para o soro controle do Kit 4. Para os soros controle dos Kits 2 e 3, foi observada grande diferença entre o valor de diluição proposto pelo fabricante para a obtenção do limiar mínimo e aquele encontrado, atingindo índice de seis diluições a menos para o Kit 2. O fabricante do soro controle do Kit 1 não determinou valor de diluição para a obtenção do limiar (Tabela 8).

\section{Avaliação do limiar de reatividade}

Tabela 8 mínima dos soros controle reagentes

\begin{tabular}{l|c|c|c|c|}
\hline $\begin{array}{l}\text { Soro } \\
\text { controle }\end{array}$ & Kit 1 & Kit 2 & Kit 3 & Kit 4 \\
\hline $\begin{array}{l}\text { Diluição } \\
\text { proposta }\end{array}$ & - & $1: 5120$ & $1: 1280$ & $1: 128$ \\
\hline $\begin{array}{l}\text { Diluição } \\
\text { encontrada }\end{array}$ & $1: 160$ & $1: 80$ & $1: 40$ & $1: 128$ \\
\hline Diferença & NA & $\begin{array}{c}6 \\
\text { diluições }\end{array}$ & $\begin{array}{c}5 \\
\text { diluições }\end{array}$ & 0 \\
\hline
\end{tabular}

NA: não avaliado.

\section{Discussão}

A padronização do teste de FAN HEp-2 é objeto de estudo há alguns anos, como demonstrado na literatura ${ }^{(2,3,8,17)}$. $\mathrm{O}$ uso de kits uniformes garante que os resultados liberados pelos laboratórios sejam precisos e reprodutíveis, fazendo que a interpretação desses resultados pelo médico seja feita de forma adequada e que o paciente não seja investigado de maneira desnecessária, no caso de resultados não reagentes ou mesmo reagentes, mas com padrões de imunofluorescência pouco ou não associados a doenças autoimunes ${ }^{(10,16,17)}$.

Neste estudo, utilizaram-se amostras constituídas pelos soros reagentes com os padrões mais prevalentes na rotina diagnóstica das instituições que os forneceram para a pesquisa. A representatividade dessa amostra pode ser garantida pelo fato de englobar amostras reagentes para os padrões mais importantes no diagnóstico das doenças autoimunes, conforme descrito na literatura ${ }^{(8)}$.

Estudo realizado em laboratório clínico da cidade de São Paulo analisou 30.728 amostras encaminhadas para triagem de autoanticorpos em FAN HEp-2 no período de dois anos. Os padrões mais prevalentes foram $\mathrm{PF}$ em baixos títulos e PFD em títulos mais altos, resultados semelhantes aos encontrados neste estudo ${ }^{(10)}$.

A taxa de concordância geral observada entre os kits foi elevada, com índice de Kappa superior 0,94. Isso demonstra que o grau de padronização em relação à apresentação dos padrões de fluorescência entre os diferentes kits pode ser considerado muito bom, existindo grande concordância entre resultados obtidos com kits de diferentes fabricantes ${ }^{(17)}$ (Tabelas 3 e 5).

Os resultados demonstraram ainda altos valores de Kappa na análise comparativa $2 \times 2$ dos kits, como também na comparação entre todos os kits, ao avaliarem os 12 padrões possíveis. Isso mostra alto grau de concordância entre as marcas diferentes para a quase totalidade dos padrões testados.

É de se notar, porém, que as menores taxas de concordância observadas foram em relação à identificação dos padrões HOMO, PF e PFD. A importância dessa discordância reside no fato de que os dois primeiros estão claramente associados a doenças autoimunes, como LES e Síndrome Sjögren, diferente do último, que não está relacionado com esse tipo de doença, não sendo recomendada a investigação sorológica subsequente do paciente com reatividade para esse padrão ${ }^{(4-7,10)}$ (Tabelas 2, 3 e 5).

O III Consenso Brasileiro para Pesquisa de Autoanticorpos em células HEp-2 contempla a possibilidade de confusão entre os padrões HOMO e PFD em determinadas amostras, em virtude das características do padrão não serem, muitas vezes, claramente discerníveis à microscopia. Como alternativa para esse problema, cogitou-se o estabelecimento de um novo padrão de imunofluorescência, o nuclear pontiIhado fino tendendo a homogêneo, com placa metafásica corada $^{(8)}$. É possível que as discordâncias observadas, em grande parte, sejam atribuídas à presença de soros com esse padrão de reatividade. Este estudo reforça a necessidade de criação e estabelecimento desse padrão específico como forma de se obter segurança na interpretação e na liberação desses resultados. A introdução desse padrão na análise realizada poderia elevar ainda mais os níveis de concordância, que, todavia, já podem ser considerados muito elevados.

Um importante critério na definição dos padrões de fluorescência pelo FAN HEp-2 é a caracterização da reatividade da placa metafásica. Quanto maior o número de mitoses encontradas por campo, mais fácil fica a caracterização da reatividade da placa e, por conseguinte, 
a definição adequada do padrão de fluorescência. Foi demonstrada grande variação em relação ao número de mitoses encontradas por campo nos diferentes kits, o que pode tornar mais difícil a definição do padrão morfológico naqueles que apresentam poucas mitoses por campo. É de se ressaltar que, além do número de mitoses presentes por campo, a facilidade de observação da mesma, seja pela intensidade da fluorescência, seja pela morfologia apresentada, é de significativa importância. No entanto, em virtude da grande possibilidade de subjetividade na definição desse critério, essa última avaliação não foi realizada (Tabela 6).

O III Consenso para Pesquisa de Autoanticorpos em células HEp-2 relata ainda a necessidade de os laboratórios realizarem a titulação dos conjugados fluorescentes utilizados na realização do teste, em virtude da heterogeneidade dos equipamentos utilizados para a leitura das lâminas. Neste trabalho, observamos que, apesar de já existirem critérios bem definidos na literatura em relação às especificações analíticas dos conjugados, ainda existe grande variação desse reagente entre os kits comerciais (Tabela 7). Portanto, torna-se necessária a verificação da intensidade da fluorescência do conjugado fluorescente, mesmo para os laboratórios que utilizam kits comerciais contendo conjugados previamente diluídos, prontos para uso. Esse critério pode ser conseguido por meio da utilização, por longo período, de um mesmo soro controle reagente no limiar de reatividade mínima, com verificação constante do mesmo, associado à verificação com lâminas comerciais com microesferas pré-calibradas para diversas intensidades de fluorescência. É importante ressaltar que, além da verificação da titulação do conjugado, referência que permite equiparar os resultados obtidos em diferentes serviços utilizando microscópios com lâmpadas de diferentes potências, é necessária a checagem rotineira das objetivas e dos filtros do microscópio que interferem na definição do título do conjugado, no controle do tempo de uso da lâmpada e em sua correta centralização $^{(8,17)}$.

Fica evidente que é importante a verificação e a conferência do valor da diluição necessária para a obtenção do limiar de reatividade mínimo no soro controle reagente fornecido em cada kit, conforme orientação do III Consenso para Pesquisa de Autoanticorpos em células HEp-2. Dois dos soros controles comerciais utilizados necessitaram de cinco e seis diluições a menos que o informado pelo fabricante para a obtenção do limiar. Esse tipo de situação deve desencadear uma série de investigações antes que esse soro controle seja utilizado de forma sistemática na rotina. A avaliação de todo o sistema, incluindo lâmpada, conjugado e soro controle, é mandatória. Caso o conjugado ou a lâmpada estejam com intensidade menor que a recomendada, haverá tendência a liberar resultados com título inferior ao real. Caso o problema esteja no soro controle do fabricante, seja pela diminuição na quantidade dos anticorpos, seja pela desnaturação, existirá a tendência a liberar resultados com títulos superiores ao real, ou seja, falso-positivos. Diante dessa situação, a realização de controle interlaboratorial, realizado com uma instituição com experiência na análise de autoanticorpos pelo método de imunofluorescência, é de grande valia, pois pode ajudar na investigação do problema ${ }^{(8,10)}$.

\section{Conclusão}

Este estudo mostra que existe elevada taxa de concordância geral, com Kappa geral superior a 0,95, evidenciando o elevado grau de reprodutibilidade em relação à observação dos padrões de fluorescência entre diferentes substratos de células HEp-2. O maior índice de discordância observado foi em relação a algumas amostras com padrão de fluorescência não muito claro, sendo classificadas como padrão HOMO, PF ou ainda PFD. Esse achado reforça a necessidade de criação de um novo padrão de FAN, conforme observação feita no III Consenso Brasileiro para Pesquisa de Autoanticorpos em Células HEp-2, que possivelmente incluiria algumas dessas amostras, aumentando a segurança na liberação e na interpretação dos resultados. Observou-se que ainda falta padronização em relação à intensidade dos conjugados fluorescentes $\mathrm{e}$ à diluição necessária para a obtenção do limiar de reatividade mínima do soro controle reagente. É preciso também que os laboratórios façam uma verificação interna desses parâmetros, sob pena de liberação de resultados que não condizem com a situação clínica do paciente, interferindo na abordagem do médico assistente.

\section{Agradecimentos}

Agradecemos ao Sr. Odair Reis, da Hemagen Diagnósticos; ao Dr. Fabiano Brito, do Laboratório Hermes Pardini; ao Dr. Carlos Alberto Von Mühlen, da Metanalysis Centro de Diagnósticos Médicos. 


\section{Referências}

1. COONS, A. H.; KAPLAN, M. H. Localization of antigen in tissue cells: II. Improvements in a method for the detection of antigen by means of fluorescent antibody. J Exp Med, v. 91, p. 1-13, 1950.

2. DELLAVANCE, A. et al. I Consenso nacional para padronização de laudos de FAN HEp-2. J Bras Patol Med Lab, v. 38, n. 3, p. 207-16, 2002.

3. DELlavance, A. et al. II Consenso Nacional para a padronização dos laudos de FAN em células HEp-2. Rev Bras Reumatol, v. 43, n. 3, p. 129-40, 2003.

4. DELLAVANCE, A. et al. The clinical spectrum of antinuclear antibodies associated with the nuclear dense fine speckled immunofluorescence pattern. The Journal of Rheumatology, v. 32, n. 11, p. 2144-9, 2005.

5. DELlaVANCE, A.; ANDRADE, L. E. C. Como interpretar e valorizar adequadamente o teste de anticorpos antinúcleo. J Bras Patol Med Lab, v. 43, n. 3, p. 15768, 2007.

6. Dellavance, A.; Leser, P. G.; ANDRAde, L. E. C. Análise crítica do teste de anticorpos antinúcleo (FAN) na prática clínica. Rev Bras Reumatol, v. 47, n. 4, p. 265-75, 2007.

7. Dellavance, A.; Leser, P. G.; ANDRAde, L. E. C. Importância do padrão de fluorescência na interpretação do teste do FAN: o caso do padrão pontilhado fino denso. Rev Assoc Med Bras, v. 53, n. 5, p. 439-45, 2007.

8. FRANCESCANTONIO, P. L. C. et al. III Consenso nacional para padronização dos laudos de FAN em células HEp-2. J Bras Patol Med Lab, v. 45, n. 3, p. 185-99, 2009.

9. HARGRAVES, M.; RICHMOND, M.; MORTON, R. Presentation of two bone marrow elements: the "tart" cell or LE cell. Mayo Clin Proc, v. 23, p. 25-8, 1948.

10. LESER, P. G. et al. Distinctive features of antinuclear antibodies observed in health and in subjects with autoimmune rheumatic diseases. In: CONRAD, K. et al. Animal models to human genetics: research on the induction and pathogenicity of autoantibodies. Dresden: Pabst Science Publishers, 2004. p. 493-510.

11. LORA, P. S. et al. Padrões de imunofluorescência do fator antinuclear (FAN) em células HEp-2 de soros reagentes para anti-SSA/Ro. Rev Bras Reumatol, v. 47, n. 1, p. 4-9, 2007.

12. MIYAKIS, S. et al. Factors contributing to inappropriate ordering of tests in an academic medical department and the effect of an educational feedback strategy. Postgrad Med J, v. 82, p. 823-29, 2006.

13. NEVES, S. P. F.; LARA, R. O laboratório nas doenças sistêmicas auto-imunes: da célula LE à célula Hep-2uma jornada de 50 anos revelando auto anticorpos. Revista Médica de Minas Gerais, Belo Horizonte, v. 14, n. 4, p. 282-8, 2004.

14. SLATER, C. A.; DAVIS, R. B.; SHMERLING, R. H. Antinuclear antibody testing: a study of clinical utility. Arch Int Med, v. 156, p. 1421-5, 1996.

15. TAN, E. M. Autoantibodies and autoimmunity: a threedecade perspective. New York Acad Sciences, v. 815, p. 1-14, 1997.

16. TAN, E. M. et al. Range of antinuclear antibodies in "healthy" individuals. Arthritis Rheum, v. 40, p. 160111, 1997.

17. VON MÜHLEN, C. A.; NAKAMURA, R. Guidelines for selecting and using laboratory tests for autoantibodies to nuclear, nucleolar and other related cytoplasmic antigens. In: NAKAMURA, R. M.; KEREN, D. F.; BYLUND, D. J. Clinical and laboratory evaluation of human autoimmune. Chicago: ASCP Press, 2002. p. 450.

18. WOLF, L. et al. Classification criteria for systemic lupus erythematosus: frequency in normal patients. JAMA, v. 236, p. 1497-9, 1976. 